\title{
Politik Luar Negeri Indonesia Di Lihat Dari UU No 37 Tahun 1999 Tentang Hubungan Luar Negeri
}

\author{
Nori Oktadewi, Wahyu \\ MIHI Universitas Muhammadiyah Yogyakarta \\ Email: norioktadewi97@gmail.com,wahyu.m.89@gmail.com
}

\begin{abstract}
Indonesia is an independent and sovereign country. In implementing foreign relations, it is certainly based on the hope of equal degrees that are mutually beneficial and respectful and do not interfere in their respective domestic affairs as implied in the 1945 Constitution. This research is quantitative. The data presented is secondary data collected from various books, articles, journals, lecturer summaries, websites and newspapers related to the Problem. The data analysis technique used is content analysis. The result of this research is that the Orientation of Law No. 37 of 1999 concerning Foreign Relations in Indonesia is more directed towards Outward, Policy maker is a Non-Hierarchy, Domestic Component ratification / legality process and actors regulated in Law No. 37 of 1999 concerning Foreign Relations in Indonesia is the State Diplomat.
\end{abstract}

Keyword: HLN, Outward, Content Analysis

\begin{abstract}
ABSTRAK
Indonesia adalah negara yang merdeka dan berdaulat. Dalam melaksankan hubungan luar negeri tentunya didasarkan pada asa kesamaan derajat yang saling menguntungkan dan menghormati serta tidak mencampuri urusan dalam negeri masing-masing seperti yang tersirat dalam UUD 1945. Penelitian ini bersifat kuantitatif. Data yang disajikan adalah data sekunder yang dikumpulkan dari berbagai buku, artikel, jurnal, ringkasan dosen, website dan surat kabar terkait Soal. Teknik analisis data yang digunakan adalah konten analisis. Hasil dari penelitian ini adalah Orientasi UU No 37 Tahun 1999 tentang Hubungan Luar Negeri di Indonesia lebih mengarah pada Outward, Policy maker bersifat Non-Hirarki, proses ratifikasi/ legalitas Domestic Component dan aktor yang di atur dalam UU No 37 Tahun 1999 tentang Hubungan Luar Negeri di Indonesia adalah State Diplomat.
\end{abstract}

Kata Kunci : HLN, Outward, konten Analisis.

\section{PENDAHULUAN}

Setiap negara mempunyai tujuan nasional yang diperoleh dengan mengelola potensi sumber daya yang terdapat baik di dalam negeri maupun di luar negeri. Dalam upaya mengelola potensi pemenuhan kebutuhan nasional yang berasal dari sumber daya yang terdapat di luar wilayah negaranya, amat penting bagi setiap negara untuk menjalin hubungan dengan negara-negara lain di tingkat internasional. Dalam menjalankan hubungan itu, setiap negara memiliki politik luar negeri, sebagai kumpulan keputusan yang diambil dalam rangka untuk mencapai tujuan nasional suatu negara. Politik luar negeri erat 
kaitannya dengan pencapaian tujuan nasional dari suatu negara. Dengan kata lain, politik luar negeri merupakan instrumen yang dimiliki oleh pemerintah suatu negara berdaulat untuk menjalin hubungan dengan aktor-aktor lain dalam politik dunia demi mencapai tujuan nasionalnya.

Dalam memperjuangkan dan mempertahankan kepentingan nasional, termasuk perlindungan kepada warga negara Indonesia di luar negeri, diperlukan upaya yang mencakup kegiatan politik dan hubungan luar negeri yang berlandaskan ketentuanketentuan yang merupakan penjabaran lebih lanjut dari falsafah Pancasila, Pembukaan dan Batang Tubuh Undang-Undang Dasar 1945 serta Garis-garis Besar Haluan Negara. Dasar pemikiran yang melandasi undang-undang tentang Hubungan Luar Negeri adalah bahwa penyelenggaraan hubungan luar negeri dan pelaksanaan politik luar negeri memerlukan ketentuan-ketentuan yang secara jelas mengatur segala aspek yang menyangkut sarana dan mekanisme pelaksanaan kegiatan tersebut. Dimana pada pembukaan Undang-Undang Dasar 1945 pada Aliena pertama yang berbunyi

"Bahwa sesungguhnya kemerdekaan itu ialah hak segala bangsa dan oleh karena itu penjajahan harus dihapuskan karena tidak sesuai dengan perikemanusiaan dan perikeadilan". ${ }^{1}$

Pernyataan tersebut menunjukkan ciri utama dari politik luar negeri Indonesia.

Dalam penyelenggaraan hubungan luar negeri dan pelaksanaan politik luar negeri, Indonesia terikat oleh ketentuan-ketentuan hukum dan kebiasaan intemasional, yang merupakan dasar bagi pergaulan dan hubungan antarnegara. Oleh karena itu Undangundang tentang Hubungan Luar Negeri ini sangat penting artinya, mengingat Indonesia telah meratifjkasi Konversi Wina 1961 tentang Hubungan Diplomatik, Konvensi Wina 1963 tentang Hubungan Konsuler, dan Konvensi tentang Misi Khusus, New York 1969. Undang-Undang Nomor 37 Tahun 1999 tentang Hubungan Luar Negeri merupakan pelaksanaan dari ketentuan dasar yang tercantum di dalam Pembukaan dan Batang Tubuh Undang-Undang Dasar 1945 dan Ketetapan-ketetapan Majelis Permusyawaratan Rakyat yang berkenaan dengan hubungan luar negeri. Undang-undang ini mengatur segala aspek penyelenggaraan hubungan luar negeri dan pelaksanaan politik luar negeri, termasuk sarana dan mekanisme pelaksanaannya, perlindungan kepada warga negara Indonesia di luarnegeri dan aparatur hubungan luar negeri.

\footnotetext{
${ }^{1}$ Republik Indonesia. 1945. Undang-Undang Dasar Negara Republik Indonesia. Jakarta Sekretaris Negara.
} 
Penyelenggaraan hubungan luar negeri dan pelaksanaan politik luar negeri melibatkan berbagai lembaga negara dan lembaga pemerintah beserta perangkatnya. Agar tercapai hasil yang maksimal, diperlukan adanya koordinasi antara lembaga-lembaga yang bersangkutan dengan Departemen Luar Negeri. Untuk tujuan tersebut, diperlukan adanya suatu peraturan perundang-undangan yang mengatur secara jelas serta menjamin kepastian hukum penyelenggaraan hubungan luar negeri dan pelaksanaan politik luar negeri, yang diatur dalam Undang-undang tentang Hubungan Luar Negeri. Undang-undang tentang Hubungan Luar Negeri ini memberikan landasan hukum yang kuat bagi penyelenggaraan hubungan luar negeri dan pelaksanaan politik luar negeri, serta merupakan penyempurnaan terhadap peraturan-peraturan yang ada mengenai beberapa aspek penyelenggaraan hubungan luar negeri dan pelaksanaan politik luar negeri. Arah politik luar negeri Indonesia adalah bebas aktif yang lebih mengkaji tentang hubungan luar negeri dan Internasional dibanding dengan kepentingan nasional.

\section{PEMBAHASAN}

Dari Latar Belakang masalah di atas tentang pembuatan kebijakan luar negeri Indonesia, maka dapat dirumuskan masalah yakni: "Bagaimana arah Politik Luar Negeri Indonesia yang tercantum dalam UU No 37 Tahun 1999 tentang Hubungan Luar Negeri?"

Dalam membahas politik luar negeri Indonesia, maka penuli melakukan review terhadap beberapa literature review

Literature pertama adalah buku Islam in Indonesia Foreign Policy yang ditulis oleh Rizal Sukma. Dalam buku ini Rizal Sukma menjelaskan bahwa kebijakan luar negeri Indonesia telah dipengaruhi oleh pertimbangan islam. Buku ini juga menyelidiki tempat dan peran dari faktor Islam dalam kebijakan luar negeri Indonesia dalam hal masalah identitas negara dan realitas dalam kelemahan negara. Kedua faktor ini berfungsi sebagai kontek utama dalam hubungan antar Islam dan kebijakan luar negeri Indonesia dapat di jelaskan dan dapat dipahami dengan lebih memuaskan. Indonesia adalah negara muslim terbesar didunia. Sehingga dengan fakta inilah orang akan mengganggap bahwa kebijakan luar negeri Indonesia akan berdasarkan Islam, namun menurut Rizal Sukma kenyataanya adalah Islam tidak pernad diadopsi untuk merumuskan kebijakan luar negeri dan politik luar negeri Indonesia, dan tidak pernah menjadi dasar untuk melakukan hubungan luar 
negeri Indonesia, namun Islam hanya berpersan sebagai agenda dan perilaku kebijakan luar negeri Indonesia bersfiat skunder, meskipun demikian hal ini tidak merugikan kepentingan Islam, hal ini dapat dilihat dari era kepemimpinan setiap presiden Indonesia. Terutama pada era Presiden Suharto. Dan Rizal Sukam menjelaskan secara rinci bagaimana pengaruh Islam di politik domestik dengan kebijakan luar negeri Indonesia, karena negara-negara barat sering membandingkan atau memisahkan urusan agama dan poltik, tetapi tidak untuk Indonesia, Islam tidak jarang dijadikan landasan untuk berpolitik, karena kemayoritasan masyarakat sehingga presiden Indonesia merasa perlu untuk merangkul komunitaskomunitas Islam. Dalam buku ini menjelaskan kebijakan luar negeri itu sendiri tergantung sifat dan kepribadian seorang pemimpin negara. ${ }^{2}$

Literature selanjutnya adalah tulisan yang berjudul Politik Luar Negeri Indonesia yang di tulis oleh Michael Leifer. Dalam buku ini menjelaskan politik luar negeri Indonesia telah dimulai sejak Indonesia merdeka. Indonesia melakukan politik luar negeri dengan harapan Indonesia mampu mampu di akui di dunia internasional. Dan kebijakan luar negeri Indonesia memang di arahkan kepada internasional, dengan titik fokus Indonesia saat itu adalah diplomasi. Dimana prakterk diplomasi didasarai dengan paksaan. Politik luar negeri Indonesia dipertahaankan dengan intervensi yang menentukan dari Soekarno dan didukung oleh Hatta. Kebijakan luar negeri Indonesia saat itu adalah politik luar negeri yang ke arah Non-Blok dimana tidak memihak pada blok Barat dan Blok Timur, dalam buku ini juga menjelaskan bahwa Indonesia memperkuat keterkaitan politikn luar negeri nya dengan cara Independen (bebas) dengan mempertahankan kedaulatan. ${ }^{3}$

Literature terakhir adalah tulisan yang berjudul : Laporan Akhir "Penyusunan Buku Pelembagaan Teorisasi Diplomatic Governance Dalam Perumusan Dan Artikulasi Politik Luar Negeri” yang ditulis Oleh Prof. Tulus Warsito dengan Ratih Hertingtyas. Dalam buku ini menjelaskan abahwa, ada tiga kesimpulan utama tentang politik luar negeri Indonesia. Pertama, Kementerian Luar Negeri Indonesia telah memiliki kemauan politik untuk menjadi organisasi yang terkelola dengan baik. Memiliki bukti dengan pencapaian ISO 2008. Kedua, diplomasi Indonesia Menunjukkan fenomena fluktuasi 10 tahun terakhir ini. Ini menunjukkan sebuah prestasi Juga membahas resesi dan korupsi. Bisa dipecahkan jika Kementerian Luar Negeri Urusan mulai mengadopsi konsep pemerintahan diplomatik, sebuah proses Pengelolaan diplomatik yang menjunjung tinggi nilai akuntabilitas,

\footnotetext{
${ }^{2}$ Sukma, Rizal. 2004 . Islam In Indonesia Foreign Policy. The Taylor \& Francis e-Library

${ }^{3}$ Leifer. M. 1989. Politik Luar Negeri Indonesia
} 
transparansi, dan keadilan. Ketiga, Perumusan dan Implementasi kebijakan luar negeri Indonesia Menggunakan paradigma tata kelola diplomatik akan meningkatkan kapasitas dan Produktivitas kebijakan luar negeri Indonesia berdasarkan Prinsip Bebas dan Aktif. ${ }^{4}$

Tulisan ini berbeda dengan literature-literature diatas, dimana tulis ini lebih fokus pada arah politik luar negeri dengan melakukan konten analisis terhadap UU Republik Indonesia Nomor 37 Tahun 1999 tentang Hubungan Luar Negeri di Indonesia.

Selain dari ketiga literature review di atas, dalam membahas tentang politik luar negeri Indonesia, penulis juga menggunakan beberapa teori.

\section{Teori Kepentingan Nasional}

Suatu negara akan tetap bertahan jika kepentingan nasional mampu terpenuhi. Tercapainya kepentingan nasional suatu negara, akan membuat segala sector akan berjalan dengan stabil seperti sector budaya, politik, ekonomi, social dan keamanan. Kepentingan nasional merupakan kunci utama dan tujuan mendasar para pembuat keputusan dalam merumuskan kebijakan luar negeri. Daniel S. Papp menjelaskan bahwa kepentingan nasional mengandung beberapa aspek penting sepertii ekonomi, ideology, moralitas, legalitas, kekuatan dan keamanan militer. $^{5}$

Kepentingan nasional (national interest) dipahami sebagai konsep kunci dalam politik luar negeri. Konsep tersebut dapat diorientasikan pada ideology suatu negara ataupun system nilai sebagai pedoman prilaku negara tersebut. Artinya bahwa keputusan dan tindakan politik luar negeri bisa didasarkan pada pertimbangan-pertimbangan ideologis ataupun dapat terjadi atas dasar pertimbangan kepentingan. Namun bisa terjadi interplay antara ideologis dan kepentingan sehingga terjalin hubungan timbal balik dan saling mempengaruhi antara pertimbangan-pertimbangan kepentingan yang tidak menutup kemungkinan terciftanya formulasi kebijakan politik luar negeri yang lain atau baru.

\section{Teori Kerjasama Internasional}

\footnotetext{
4 Warsito, Tulus.2015. Laporan Akhir "Penyusunan Buku Pelembagaan Teorisasi Diplomatic Governance Dalam Perumusan Dan Artikulasi Politik Luar Negeri”. UMY-Yogyakarta

5 Papp, Daniel S. 1988. Contemporary International Relation" : A Framework for Understanding Second Edition. New York : MacMillan Publishing Company.
} 
Setiap negara diberbagai penjuru dunia tidak dapat berdiri sendiri dan perlu kerjasama dengan negara lai, karena adanya ketergantungan antara negara satu dengan negara lainnya, dilihat dari kebutuhan negara masing-masing. Kerjasama internasional dapat dilakukan melalui sector social, ekonomi, politik, budaya dan keamanan.

Menurut K. J Holsti, kerjasama inetrnasional terbentuk dari perpanduan keanekaragaman masalah nasional, regional, ataupun global yang muncul dan memerlukan perhatian serta penyelesaian dari berbagai negara. Kerjasama internasional mampu meningkatkan kesejahteraan bersama dan mampu menyelesaikan masalah yang dihadapi lebih cepat. K. J Holsti juga memaparkan bahwa kerjasama internasional dapat didefiniskan sebagai pandangan atau harapan dari suatu negara bahwa kebijakan yang diputuskan oleh negara lain akan membawa dampak baik bagi negaranya. Kerjasama internasional juga bagian dari transaksi antar negara untuk memenuhi persetujuan mereka. ${ }^{6}$

a. Hipotesa

Arah Politik Luar Negeri Indonesia tercantum dalam UU No 37 Tahun 1999 tentang Hubungan Luar negeri :

1. Orientasi UU No 37 Tahun 1999 tentang Hubungan Luar Negeri di Indonesia lebih mengarah pada Outward.

2. Policy maker UU No 37 Tahun 1999 tentang Hubungan Luar Negeri di Indonesia bersifat Non-Hirarki

3. Proses ratifikasi/ legalitas No 37 Tahun 1999 tentang Hubungan Luar Negeri di Indonesia lebih mengarah pada Domestic Component.

4. Aktor yang di atur dalam No 37 Tahun 1999 tentang Hubungan Luar Negeri di Indonesia adalah State Diplomat.

b. Hasil

a. Deskripsi UU Republik Indonesia No 37 Tahun 1990 tentang Hubungan Luar Negeri

Indonesia adalah negara yang merdeka dan berdaulat. Dalam melaksankan hubungan luar negeri tentunya didasarkan pasa asa kesamaan derajat yang saling menguntungkan dan menghormati serta tidak mencampuri urusan dalam negeri masing-

\footnotetext{
${ }^{6}$ Holsti. K.J. 1988. Politik Internasional, Kerangka Untuk Analisis, Jilid II, Terjemahan M. Tahrir Azhari. Jakarta: Erlangga.
} 
masing seperti yang tersirat dalam UUD 1945. Pada pembukan UUD 1945 Indonesia ikut melaksankan ketertiban dunia yang berdasarkan kemerdekaan perdamaian dan keadilan social. Sehingga untuk mencapai tujuan itu, Indonesia harus melakukan hubungan luar negeri dengan berbagai negara serta bekerjasama dengan Organisasi Regional maupun Organisasi Internasional. Politik luar negeri Indonesia adalah bebas aktif, dimana pelaksanaan hubungan luar negeri baik regional maupun internasional dilakukan melalui forum bilateral dan multilateral. Sehingga untuk meningkatkan hubungan luar negeri dan mencapai politik luar negeri tetap terjaga, penyelenggaraan hubungan luar negeri diatur dalam suatu UU yaitu UU Tentang Hubungan Luar Negeri.

Undang-Undang tentang Hubungan Luar Negeri berdasarkan pada Pasal 5 ayat (1), Pasal 11, Pasal 13, dan Pasal 20 ayat (1) Undang-Undang Dasar 1945. Disisi lain berdasarkan pada Undang-Undang Nomor 1 Tahun 1982 tentang Pengesahan Konvensi Wina mengenai Hubungan Diplomatik beserta Protokol Opsionalnya mengenai Hal Memperoleh Kewarganegaraan (Vienna Convention on Diplomatic Relations and Optional Protocol to the Vienna Convention on Diplomatic Relations Concerning Acquisition of Nationalily), 1961 dan Pengesahan Konvensi mengenai Hubungan Konsuler beserta Protokol Opsionalnya mengenai Hal Memperoleh Kewarganegaraan (Vienna Convention on Consular Relations and Optional Protocol to the Vienna Convention on Consular Relations Concerning Acquisition of Nationality), 1963 (Lembaran Negara Republik Indonesia Tahun 1982 Nomor 2; Tambahan Lembaran Negara Republik Indonesia Nomor 3211). Serta berdasarkan Undang-undang N omor 2 Tahun 1982 tentang Pengesahan Konvensi Mengenai Misi Khusus (Convention on Special Mission), New York, 1969 (Lembaran Negara Republik Indonesia Tahun 1982 Nomor 3; Tambahan Lembaran Negara Republik Indonesia Nomor 3212). ${ }^{7}$

Hubungan internasional tidak lagi dilakukan oleh negara namun dilakukan aktor yang beragam seperti IGO dan NGOs, sehingga dengan adanya aktor-aktor ini hubungan internasional semakin universal. Walaupun demikian, negara tetap menjadi peran penting dalam hubungan internasional.

\section{b. Konten Analisis UU Hubungan Luar Negeri.}

Dalam konten analisisi ini, penulis menggunakan beberapa Indikator untuk menganalisis beberapa tolak ukur yang yang mencangkup Orientasi, prosedur, proses

\footnotetext{
${ }^{7}$ UU Republik Indonesia No 37 Tahun 1999 tentang Hubungan Luar Negeri.
} 
ratifikasi/ legalitas maupun aktor yang diatur dalam UU Nomor 37 Tahun 1999. Berikut adalah beberapa indicator beserta coding yang digunakan : Orientasi (Inward dan Outward), prosedur (Hirarki dan non Hirarki), proses legalitas (Internasional Compenent dan Domestic kompenen), Aktor (Sate Diplomat dan Citizen Diplomat).

Tabel 1. Indikator Orientasi UU Hubungan Luar Negeri

\begin{tabular}{|c|c|c|c|c|c|c|c|c|c|c|c|}
\hline \multicolumn{6}{|c|}{ INWARD } & \multicolumn{6}{|c|}{ OUTWARD } \\
\hline MKB & KN & $\mathrm{HN}$ & PL & KB & PE & KD & OI & HLN & DP & PLN & \\
\hline 0 & 3 & 0 & 4 & 3 & $\mathbf{0}$ & $\mathbf{0}$ & 10 & 23 & 1 & 13 & \\
\hline \multicolumn{6}{|c|}{$10(11.63 \%)$} & \multicolumn{5}{|c|}{ JUMLAH } & \\
\hline \multicolumn{12}{|c|}{ Keterangan } \\
\hline \multicolumn{6}{|c|}{ Inward: } & \multicolumn{6}{|c|}{ Ourward: } \\
\hline ID & \multicolumn{5}{|c|}{ : Identitas Budaya } & \multicolumn{6}{|c|}{ KD : Keterlibatan Dunia } \\
\hline $\mathrm{MKB}$ & \multicolumn{5}{|c|}{ : Memperkenalkan budaya } & \multicolumn{6}{|c|}{ OI : Organisasi Internasional } \\
\hline $\mathrm{KN}$ & \multicolumn{5}{|c|}{ : Kepentingan Nasional } & \multicolumn{6}{|c|}{ HLN : Hubungan Luar Negeri } \\
\hline $\mathrm{HN}$ & \multicolumn{5}{|c|}{ : Hukum Nasional } & \multicolumn{6}{|c|}{ DP : Diplomasi } \\
\hline PL & \multicolumn{5}{|c|}{ :Perlindungan } & \multicolumn{6}{|c|}{ PLN : Politik Luar Negeri } \\
\hline KB & \multicolumn{5}{|c|}{ : Kebijakan } & \multicolumn{6}{|c|}{ ITL : Internasional } \\
\hline PE & \multicolumn{5}{|c|}{ : Perekonomian } & \multicolumn{6}{|c|}{ : Persahabatan } \\
\hline
\end{tabular}

Tabel 2. Indikator Prosedur UU Hubungan Luar Negeri

\begin{tabular}{|c|c|c|c|c|c|c|}
\hline \multicolumn{3}{|c|}{ HIRARKI } & \multicolumn{3}{c|}{ Non-HIRAKRKI } \\
\hline BP & CT & GBR & KPD & PRS & MNT & DPR \\
\hline O & 0 & 0 & 0 & 24 & 23 & 4 \\
\hline JUMLAH & & & 0 & JUMLAH & $51(100 \%)$ & \\
\hline
\end{tabular}

Keterangan

Hirarki :

BP : Bupati

CT : Camat

GBR : Gubernur

KPD : Kepala Desa

\section{NON-HIRARKI :}

PRS :Presiden

MNT : Menteri

DPR : Dewan Perwakilan Rakyat

Tabel 3. Indikator Proses Ratifikasi/ Legalitas UU Hubungan Luar Negeri

\begin{tabular}{|c|c|c|c|c|c|c|c|}
\hline \multicolumn{1}{|c|}{ INTERNASONAL COMPENENT } & \multicolumn{5}{|c|}{ DOMESTIC COMPONENT } \\
\hline MGT & PRD & PNY & PGS & PLK & KS & LP & LN \\
\hline 1 & 0 & 0 & 5 & 8 & 2 & 3 & 3 \\
\hline JUMLAH & 1 & $(4,54 \%)$ & JUMLAH & \multicolumn{7}{|c|}{$21(94,46 \%)$} \\
\hline
\end{tabular}

Keterangan

Internsional Compenent :

MGT : Mengikuti

PRG : Perlindungan

PNY : Penyesuaian

Domestik Kompenent :
PGS : Pengesahan
PLK : Pelaksanaan
KS : Konsultasi
LP : Lembaga Pemerintah
LN $\quad$ : Lembaga Negara

Tabel 4. Indikator Aktor yang diatur dalam UU Hubungan Luar Negeri

\begin{tabular}{|c|c|c|c|c|c|c|c|c|c|c|c|}
\hline \multicolumn{5}{|c|}{ State Diplomat } & \multicolumn{3}{c|}{ Citizen Diplomat } \\
\hline DPR & PP & MTR & PJ & MNC & BO & SO & OR & LSM & PRP & OM & IL \\
\hline 4 & 10 & 23 & 19 & 0 & 0 & 2 & 1 & 0 & 1 & 1 & 0 \\
\hline \hline JUMLAH & $56(90.32 \%)$ & JUMLAH & 6(9.68\%)
\end{tabular}


Keterangan

\section{State Diplomat}

DPR : Dewan Perwakilan Rakyat

PP : Perwakilan Pemerintah

MTR : Menteri

PJ : Pejabat

Citizen Diplomat
MNC : Multi Nasional Company
BO : Beberapa Orang
SO : Seseorang
OR : Organisasi Regional
LSM : Lembaga Swadaya Masyarakat
PRP $\quad$ : Partai Politik
OM $\quad$ : Organisasi Masyarakat
IL $\quad$ : Ilmuwan

Tabel 5. Komparasi 4 Indikator

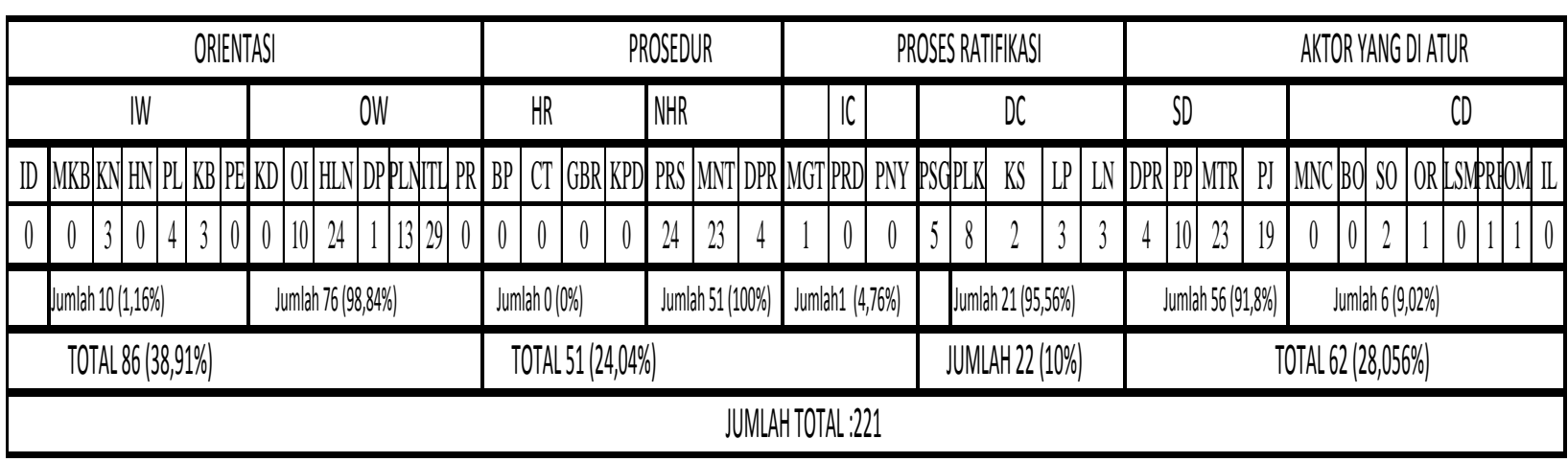

\section{c. Analisis Hasil Coding}

Berdasarkan table perhitungan indicator Orientasi dengan menggunkan sejumlah keyword, di temukan bahwa orientasi UU Hubungan Luar Negeri Indonesia mengacu pada orientasi Outward. Dengan arti lain bahwa politik luar negeri Indonesia didominasi oleh orientasi yang mengarah pada arah internasional dari pada kea rah domestic atau dalam negeri, alasan ini karena penulis melihat dari sejumlah keyword yang digunakan untuk membandingkan arah orientasi UU Hubungan Luar Negeri apakah mengarah ke Outward atau Inward. Keywor Inward seperti Kepentingan nasional, Identitas Budaya, Memperkenalkan budaya, Hukum Nasional, Perlindungan, Kebijakan, dan Perekonomian. Sedangkan outward nya antara lain adalah keamanan dunia, organisasi internasional, internasional, hubungan luar negeri, diplomasi, persahabatan serta politik luar negeri. Dengan cara mendeteksi dan menghitung banyaknya kemunculan keyword dalm Hubungan Luar Negeri , sehingga dapat ditemukan bahwa beberapa keyword yang terkait dengan objektif cakupan maupun sarana prasarana, sebagaian besar mengarah pada orientasi outwar dengan persentase sebesar $88.37 \%$. Sedangkan orientasi Inward hanya meperoleh persentase sebesar $11.63 \%$. Sehingga dalam hal ini dapat disimpulkan bahwa perpolitikan luar negeri Indonesai di lihar dari indicator orientasi dengan keyward Inward 
dan outward domeinan kea rah luar yang tercantum dalam aturan hukum yang dibuat oleh pemerintah Indonesia.

Dalam perhitungan table prosedur pembuatan UU Hubungan Luar Negeri di Indonesia bersifat non Hirarki atau tidak menggunakan system berjenjang, dimana pembuatan UU Hubungan Luar Negeri secara penuh dilakukan oleh pemerintah pusat yaitu Presiden, Menteri dan DPR. Dan pemerintah daerah sama sekali tidak ikut andil dalam pembuatan UU Hubungan Luar Negeri. Pernyataan ini dapat di temukan dalam perhitungan tabel prosedur Pembuatan UU Hubungan Luar Negeri, dimana dalam menganalisis proosedur pembuatan UU Hubungan Luar Negeri digunakan dua Indikator yakni Hirarki dan non Hirariki. Dimana Hirarki menggunakan keyword : Gubernur, camat, bupati dan kepala desa, serta Non Hiraki menggunakan keyword : presiden, menteri dan DPR. Sehingga dari penggunaaan keyword tersebut terdeteksi dan dihitung secara rinci maka hasil persentase Hirarki sebanyak 0\% sedangkan Non-Hirarki sebanyak 100\%. Sehingga dapat di simpulakan bahwa dalam pembuatan UU Hubungan Luar Negeri adalah wewenang Presiden dan Menteri. Dan pemerintah daerah memang tidak ikut andil dalam pembuatan UU Hubungan Luar Negeri.

Dilihat dari tahap ratifikasi adalah tahap yang paling penting dalam seluruh proses pembuatan perjanjian atau perpolitikan internasional. Karena hal inilah yang membuat suatu negara mengikat dirinya secara definitive pada suatu perjanjian internasioal. Dimana dalam pembuatan UU HubungaN Luar Negeri Indonesia terlihat lebih mengarah pada Domestik Komponen dari pada Internasional Kompenen. Karena dalam pengesahan UU Hubungan Luar Negeri sebagaian besar tengtang perangkat, prosedur, system maupun cara pengesahan, yang mengatur adalah perangkat-perangkat dalam negeridibandingkan internasional komponen. Dengan dilihat dari beberapa keyword untuk membandingkan international component dan domestic component. Keyword International component adalah menikuti, perlindungan dan penyesuaian. Sedangkan keyword untuk domestic component adalah pengesahan, pelaksanaan, konsultasi, lembaga negara dan lemabaga pemerintah. Dari penghitungan keyword diatas kemudian mengasilkan 95.46\% konten UU Hubungan Luar Negeri didominasi oleh domestic component sedangkan international compenent hanya 4. 54\% dalam proses ratifikasi UU Hubunga Luar Negeri. Sehingga dapat disimpulkan bahwa proses ratifikasi UU Hubungan Luar Negeri di Indonesia di atur oleh Domestic Component. 
Dan berdasarkan penghitungan Aktor yang diatur oleh UU Hubungan Luar Negeri, juga menggunakan dua indicator yakni State Diplomat dengan keyword DPR, pejabat, perwakilan pemeritah dan menteri. Indicator lain adalah Citizen Diplomat dengan Keyword Multi Nasional Company, Beberapa Orang, Seseorang, Organisasi Regional, Lembaga Swadaya Masyarakat, Partai Politik, Organisasi Masyarakat, dan Ilmuwan. Setelah melakukan penghitungan maka sebanyak 90.32\% konten UU Hubungan Luar Negeri didominasi oleh state diplomat sedangkan 9.68\% konten UU Hubungan Luar Negeri yang menerangkan tentang citizen diplomat. Dari penulusuran konten Hubungan Luar Negeri, keyword mengenai citizen diplomat hanya diterangkan secara general dengan mengunakan diksi kata yang disebutkan diatas, sehingga dapat disimpulkan bahwa aktoraktor yang dapat melakukan politik luar negeri yang di atur dalam UU NO 37 TAHUN 1999 tentang Hubungan Luar Negeri Indonesia sebagain besar menagarah pada state diplomat daripada citizen diplomat. Namun UU Hubungan Luar Negeri mesih mengatur tentang pemberian kesempatan pada warga negara untuk berperasa sebagai aktor dalam politik luar negeri.

Sehingga dari keempat indicator di atas, berdasarkan sejumlah tabel penghitungan indicator dan analisis data, dapat dsimpulkan bahwa arah perpolitiakn luar negeri Indonesia yang bebas aktif telah didukung dan di tunjang oleh orientasi outward. Dimana orientasi ini telah dideteksi dari konten yang tercantum dalam UU No 37 Tahun 1999 tentang Hubungan Luar Negeri, dimana dapat dilihat bahwa orientasi poltik luar negeri Indonesia mengarah pada orientasi yang berfokus pada kearah luar negeri dan bukan berfokus pada dalam negeri yang mencirikan negara Isolasi dan protektif. Dimana konten Outward dapat dilihat bahwa UU ini lebih banyak membahasa tentang lingkup internasional dari pada lingkup domestic dan kepentingan nasional. Dan orientasi ini juga juga didukung dengan aturan tertulis dalam UU no 37 Tahun 1999 terkait dengan legalitas arau ratifikasi Hubungan Luar Negeri yang secara rinci mengga mbarakan tentang perangkat domestic yang melakukan proses ratifikasi, monitori dan rule making maupun reporting, dengan cara inilah state diplomat dapat melakukan politik luar negeri.

Dilihat dari prosedur dalam pembuatan Undang-Undang Hubungan luar negeri, prosedurnya bersifat Non-Hierarki dimana yang berwewenang hanyalah Presiden, Menteri dan DPR saja, diaman pemerintah daerah tidak ikut andil dalam proses pembuatan UU Hubungan Luar Negeri, dan aktor nya hanya mengarah kepada state diplomat. Sehingga politik bebas aktif Indonesia masih belum dapat dijalankan secara maksimal, jika mengacu 
prosedur dan aktor. Seharusnya sebagai negara yang menjalakan politik luar negeri yang bebas aktif, aturan hukum di Indonesia juga harus membahas tentang pemberian kesempatan yang lebih besar kepada warga negara serta pemerintah daerah untuk berperan dalam hal hubungan internasional dengan terlibat langsung dalam prosedur pembuatan UU Hubungan Luar Negeri.

Selain dari konten analisis tentang UU Republik Indonesia Nomor 37 Tahun 1999 tentang Hubungan Luar Negeri, yang menunjukan kalau arah politik luar negeri mengarah ke outward, adapun buktik-bukti yang menunjukan bahwa UU Hubungan Luar Negeri Indonesia mengarah ke Outwar adalah telah diketahui oleh dunia, politik luar negeri Indonesia terkenal dengan Politik bebas aktif. Politik luar negeri Indonesia sejak merdeka mengalami pasang surut, meskipun demikian namun pada akhirnya tetap politik luar negeri yang bebas dan aktif. Pengalaman sebagai bangsa yang terjajah, terikat kemerdekaannya dan kebebasannya selama kurang lebih 350 tahun telah cukup untuk tidak terulang kembali setelah Indonesia melepaskan diri dari penjajah. Pengalaman ini telah sifat kewaspadaan nasional pada bangsa Indonesia khususnya dibidang hubungan poliik luar negeri Indoesia bertahan untuk tidak memihak kepada negara manapun dengan maksud meminta bantuanbantuan untuk turut serta melakukan perlawanan terhadap kolonialisme yang hendak dipaksakan kembali kepada bangsa Indonesia, sekalipun keadaan Indonesia sangat memprihatinkan. Pemerintah berpendapat pendirian yang harus kita ambil ialah supaya kita jangan menjadi objek dalam pertarungan politik internasional, melainnkan kita harus tetap menjadi subyek yang berhak menentukan sikap kita sendiri, berhak mmperjuangkan tujuan kita sendiri, yaitu Indonesia merdeka seluruhnya. ${ }^{8}$

Politik luar negeri Indonesia prinsip aktif dapat kita temukan sumbernya dalam pembukaan UUD 1945 alenia ke-empat antara lain berbunyi :

"Kemudian daripada itu untuk membentuk suatu Pemerintahan Negara Indonesia yang melindungi segenap bangsa Indonesia dan seluruh tumpah darah Indonesia dan untuk memajukan kesejahteraan umum, mencerdaskan kehidupan bangsa, dan ikut melaksanakan ketertiban dunia yang berdasarkan kemerdekaan perdamaian abadi dan keadilan sosial. , 9

Berdasarkan perkataan di atas bahwa negara RI harus ikut melaksanakan suatu kewajiban dunia yang dicita-citakan oleh Revolusi Indonesia. Politik luar negeri Indonesia

\footnotetext{
${ }^{8}$ Michael Leifer, Politik Luar Negeri Indonesia, 1989, hal. 30

${ }^{9}$ Dudy Singadilaga. S.H. M, Pa. Politik Luar Negeri Indonesia. 1973. Hal. 20
} 
harus aktif bukan sesuatu yang diharapkan sikap dan tindakan yang pasif. Aktif di sini adalah suatu kegiatan yang terarah turut serta dengan kegiatan-kegiatan internasional yang menuju kepada terbentuknya ketertiban dunia baru. Yang mempunyai tiga unsur dasar yaitu kemerdekaan, perdamaian abadi dan keadilan sosial. Sedangkan bebas yaitu bebas mengadakan hubungan dengan negara manapun dalam arti bebas menentukan sendiri sikap dan keputusankeputusan terhadap masalah-masalah internasional menurut nilai dan manfaatnya masing-masing tanpa mengikatkan diri kepada suatu blok. Haluan politik LN yang digariskan Proklamator RI pada prinsipnya tidak ingin menjadi obyek dalam percaturan internasional. Indonesia harus dapat menjadi subyek yang dapat menentukan kebijakannya sendiri. Prinsip bebas dan aktif dipilih untuk menolak tuntutan sayap kiri agar Indonesia berkiblat ke Uni Soviet dan di sisi lain untuk membuat jarak dengan Amerika Serikat (AS). Sikap bebas dan aktif ini juga mendefinisikan peranan yang tepat bagi Indonesia dalam konflik antara dua negara adi kuasa tersebut. Sejak kemerdekaan, eksistensi negeri yang masih belia ini mendapat tantangan dari Belanda. Perjuangan dengan melakukan diplomasi untuk memperjuangkan pengakuan internasional atas kemerdekaan dan upaya mencegah kembalinya kekuasaan kolonial telah menjadi ciri pelaksanaan politik luar negeri pada masa awal berdirinya RI.

\section{KESIMPULAN DAN SARAN}

Hubungan Luar Negeri diselenggarakan sesuai dengan Politik Luar Negeri, peraturan perundang-undangan nasional dan hukum serta kebiasaan internasional, berlaku bagi semua penyelenggara hubungan luar negeri, baik pemerintah maupun nonpemerintah. Disisi lain Presiden dapat menunjuk pejabat negara selain Menteri Luar Negeri, pejabat pemerintah, atau orang lain untuk menyelenggarakan hubungan luar negeri di bidang tertentu. Dalam melaksanakan tugasnya, pejabat negara selain Menteri Luar Negeri, pejabat pemerintah atau orang lain untuk melakukan konsultasi dan koordinasi dengan Menteri. Berkaitan dengan Aparatur Hubungan Luar Negeri, Menteri menyelenggarakan sebagian tugas umum pemerintahan dan pembangunan dalam bidang Hubungan Luar Negeri dan Politik Luar Negeri. Koordinasi dalam penyelenggaraan Hubungan Luar Negeri dan pelaksanaan Politik Luar Negeri diselenggarakan oleh Menteri. Arah politik luar negeri Indonesia yaitu bebas aktif, sehingga Orientasi UU No 37 Tahun 1999 tentang Hubungan Luar Negeri di Indonesia lebih mengarah pada Outward, Policy maker UU No 37 Tahun 1999 tentang Hubungan Luar Negeri di Indonesia bersifat Non- 
Hirarki, Proses ratifikasi/ legalitas No 37 Tahun 1999 tentang Hubungan Luar Negeri di Indonesia lebih mengarah pada Domestic Component, Aktor yang di atur dalam No 37 Tahun 1999 tentang Hubungan Luar Negeri di Indonesia adalah State Diplomat.

Saran dari penulis adalah UU Hubungan Luar Negeri perlu di amandemen atau diubah, karena dilihat dari pembuatan UU pada tahun 1999, UU Hubungan Luar Negeri Indonesia belum pernah di Amandemen dan belum ada perubahan sama sekali. Karena telah diketahui bahwa seiring dengan perkembangan globalisasi, diplomasi dan politik luar negeri saat ini dapat dilakukan oleh aktor-aktor non pemerintah. Sehingga aktor-aktor non pemerintah juga perlu di atur dalam UU Hubungan Luar Negeri dan disisi lain telah diketahui bahwa politik luar negeri terjadi adalah untuk mencapai kepentingan nasional, namun dalam UU Hubungan Luar Negeri Indonesia sendiri juga tidak mengarah ke inward looking namun lebih pada outward looking. Serta saat ini juga pemerintah daerah atau provinsi juga terlibab dan mampu untuk membentuk hubungan dengan negara lain, dan hendak nya dalam pembuatan UU Hubungan luar negeri juga perlu dilibatkan pemerintah daerah atau provinsi. Dalam artian lain UU Republik Indonesia Nomor 37 tahun 1999 tentang Hubungan Luar Negeri memang perlu di Amandemen.

\section{DAFTAR PUSTAKA}

\section{Buku/Jurnal :}

Dudy Singadilaga. S.H. M, Pa. Politik Luar Negeri Indonesia. 1973

Holsti. K.J. 1988. Politik Internasional, Kerangka Untuk Analisis, Jilid II, Terjemahan M. Tahrir Azhari. Jakarta: Erlangga

Leifer. M. 1989. Politik Luar Negeri Indonesia.

Papp, Daniel S. 1988. Contemporary International Relation" : A Framework for Understanding Second Edition. New York : MacMillan Publishing Company

Oktadewi, Nori. 2017. Tugas : Konten Analisis Undang-Undang No37 Tahun 1999 tentang Hubungan Luar Negeri.

Sukma, Rizal. 2004. Islam In Indonesia Foreign Policy. The Taylor \& Francis e-Library

Warsito, Tulus.2015. Laporan Akhir "Penyusunan Buku Pelembagaan Teorisasi Diplomatic Governance Dalam Perumusan Dan Artikulasi Politik Luar Negeri”. UMY-Yogyakarta 


\section{Sumber Undang-Undang :}

Republik Indonesia. 1945. Undang-Undang Dasar Negara Republik Indonesia. Jakarta Sekretaris Negara.

Republik Indonesia. Undang-Undang Republik Indonesia Nomor 37 Tahun 1999 tentang Hubungan Luar Negerei Indonesia. Republik Indonesia Tahun 1999. 